\title{
An Analytical Model on Business Diffusion
}

\author{
Thakur Dhakal \\ Department of Industrial Engineering, Kangwon National University, South Korea \\ E-mail: thakur_dhakal2003@kangwon.ac.kr
}

Received 15 May 2018; Accepted 30 January 2019;

Publication 21 March 2019

\begin{abstract}
The diffusion is the process where innovation is communicated through the certain channels among the members of the social systems in certain time [1]. This paper presents a simple analytical business diffusion model when the social environment has not turmoil change and be in the constant clam. This study also proposes a mental model of business dynamics on business extension, with respect to sales volume at a certain community through certain channel. The analytical model was analysed with Apple iPhone sales data [2] of period 2007 to 2017 and compared with Bass [3] diffusion found a better fit while estimating the parameters using nonlinear least square(NLS) method.
\end{abstract}

Keywords: Business, Diffusion, Innovation, Potential Market, Mental Model.

\section{Introduction}

While launching a new business/technology the innovators are serious about its future, thus the business diffusion analysis is an interesting research problem. Though there are many similar existing businesses, the penetration of the market and its sustainability is most important. In the new product technology diffusion, a fraction of potential customers is the first users who accept the product and they play the role to trigger the diffusion of product through

Journal of Industrial Engineering and Management Science, Vol. 1, 119-128. doi: 10.13052/jiems2446-1822.2018.007

This is an Open Access publication. (c) 2019 the Author(s). All rights reserved. 
the community [3]. The diffusion of innovation [1] segmented the market share of the new product in five different stages as innovators, early adopters, early majority, late majority, and laggards as in Figure 1. The innovation has characteristics as relative advantage, Compatibility, triability, observability, complexity [1].

The diffusion study in marketing introduced in the 1960s as [2, 4-8]. Then numbers of researchers had contributed to diffusion study. The bass [2] is the most cited and the pioneer model in marketing literature where the total adopters were decided with innovators and imitators. Based on the Bass model framework there are many updated models as [9-12] which are all effective for forecasting product sales with individual behaviour of the product. The multigeneration product diffusion was studied as [13-19]. Most of the diffusion models were based on multiple constant parameters as $[2,20-22]$ and time varying parameters as [23-27]. As in the Bass model, there are innovative and imitative coefficients which can be calculated but all business characteristics act as a single effort in the real diffusion process.

Thus, this paper proposes a diffusion model with a single constant parameter which represents all business characteristics as price, policy, word of mouth, advertisement effectiveness, seasonal factors, customer choice and behaviour and so on. This model is also based on the traditional definition of diffusion which is the process where innovation is communicated through certain channels among the members of social system in a certain time [1].

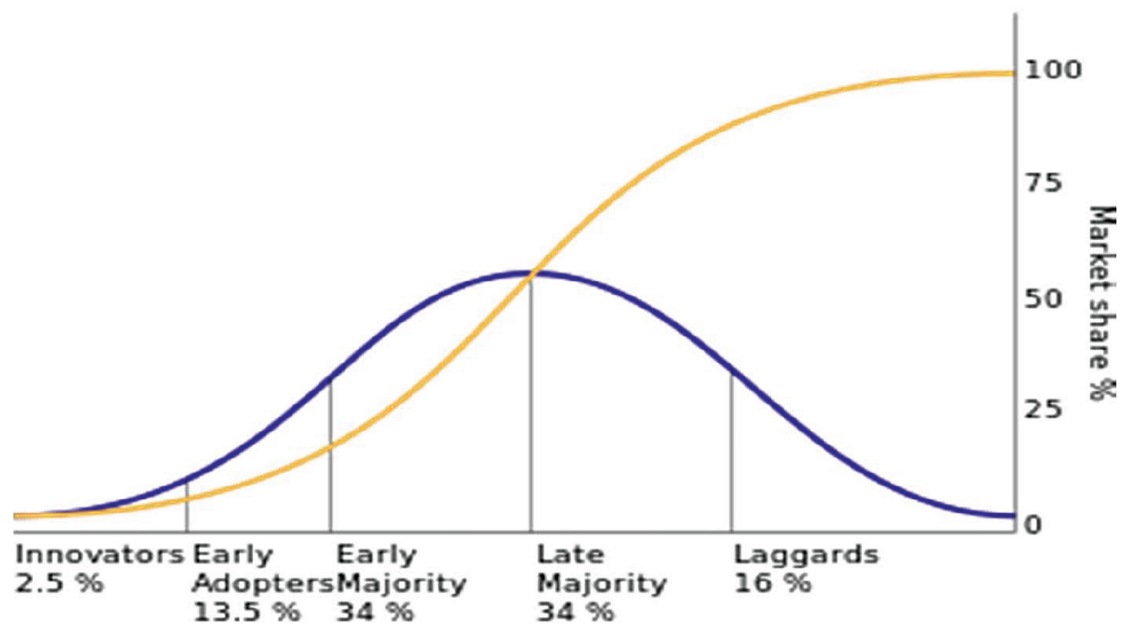

Figure 1 Diffusion of Innovation [1]. 
The contribution of this paper is to propose a simple business diffusion model, which spread with certain channels. The paper also introduced a conceptual mental model with causal loop diagram on business diffusion.

\section{The model}

The business is launched with the new strategy and new concepts to compute the competitive market under the national legislation umbrella and its extension with their agent-ship with satisfying their product as dealer and sub-dealers which increases as per the requirements and spread to all potential consumers. A simple mental model with causal loop diagram of the proposed mathematical diffusion model is shown as in Figure 2. The advertisement, schemes, and strategies help to impress the users and increase the sales volume. Similarly, the feedback effect, which motivates users as well as the business holder and helps to extend the market.

The business diffusion model is designed under some assumptions as;

1. Constant social cognition.

2. The adoption rate depends on the contact rate.

3. The social media influence rate is the same in all direction and network.

4. The social environment has not turmoil change and be in the constant clam then the new business diffusion is proportional 'to the contact ratio about the products and schemes' to each person and the advertisement effect through different media.

The expected diffusion capacity be $\mathrm{m}$ (estimated from the survey), the initial diffusion is slow because nobody knows about the technology initially they will aware and make the specific users by the innovators. The average rate of

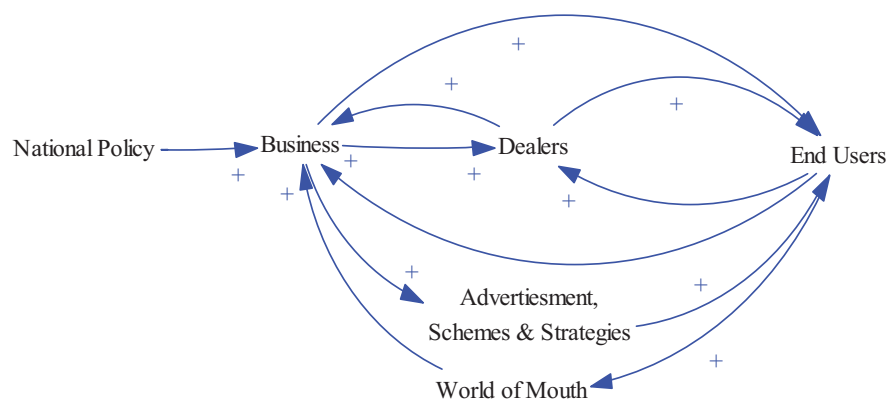

Figure 2 Simple mental model of business dynamics. 


\section{Thakur Dhakal}

adoption per unit time among expected people for this initial state be $\alpha$ per unit small time $d \tau$ where $0<\tau<t$. t be the expected time of diffusion on the expected market then the total small adopted people in time $d \tau$ is $d N$

$$
d N=m * \alpha d \tau
$$

This adopted people [1] diffuse the technology with combine (innovator and imitator) effect together then the diffusion rate will be $\beta$ per unit time per unit-adopted people. The change in adopted people can be written as;

$$
d m_{d}=(\beta(t-\tau) d N
$$

Simplifying with Equation [1] the Equation [2] becomes;

$$
d m_{d}=m \alpha \beta(\mathrm{t}-\tau) * d \tau
$$

If we integrate the Equation [3] from 0 to $t$ and considered initial value as zero then;

$$
m_{d}=\frac{m \alpha \beta t^{2}}{2}
$$

This diffused population on Equation [4] is not perfect; it also included some refused adopters data because of the random distribution of social status and population. The real adopted people per each time increment is proportional to the fraction of not adopted population. Then the real small-adopted people per unit time will be;

$$
d m_{r}=d m_{d}\left(1-\frac{m_{r}}{m}\right)
$$

Rearranging and integrating the Equation [5] becomes;

$$
\log (1-\mathrm{X})=\frac{\mathrm{m}_{\mathrm{d}}}{m}
$$

where $\mathrm{X}=$ diffusion fraction $=m_{r} / m$

Then,

$$
X=1-\exp \left(-\frac{\mathrm{m}_{\mathrm{d}}}{m}\right)
$$

Or

$$
X=1-\exp \left(-\frac{\alpha \beta t^{2}}{2}\right)
$$

Further simplification:

$$
X=1-\exp \left(-k t^{2}\right)
$$

Where, constant $k=\frac{\alpha \beta}{2}$

The cumulative diffusion fraction of the business depends upon the square of time and business characteristic constant $k$. 


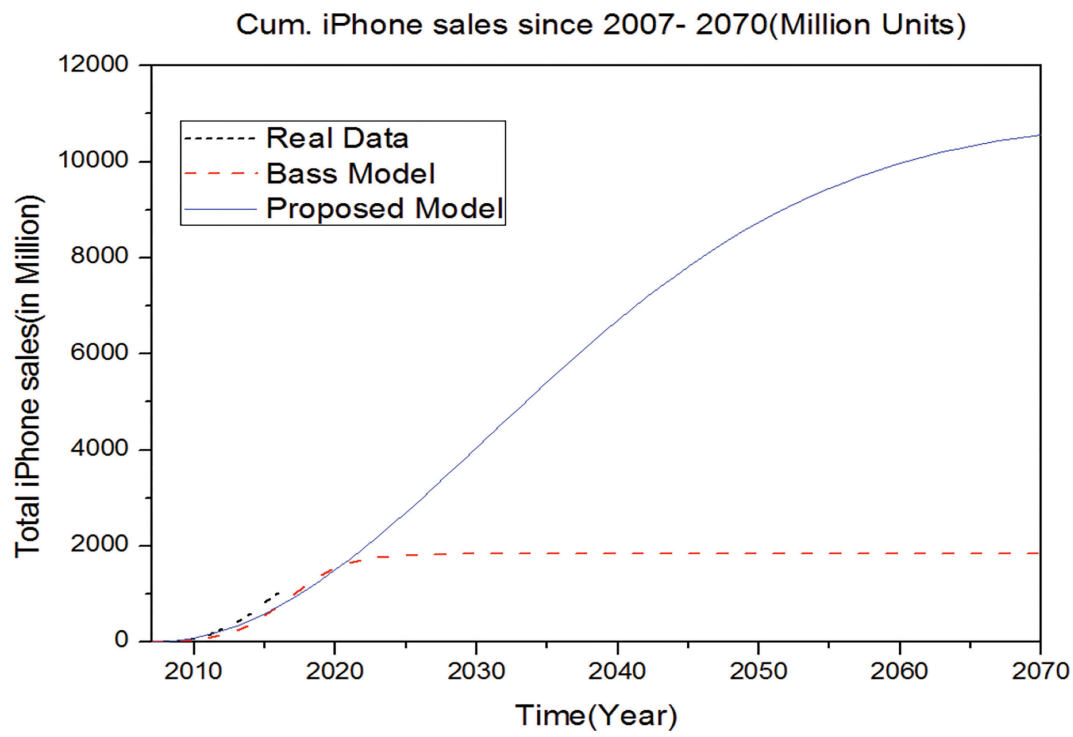

Figure 3 Cum. sales diffusion with different models.

Source: https://www.statista.com/statistics/216459/global-market-share-of-apple-iphone/

\section{Analysis}

The proposed model was examined with the iPhone sales data from 2007-2017 [2]. While estimating the parameters using NLS, the potential sales of iPhone was $1.2 \mathrm{e}+4$ million and the value of constant $\mathrm{k}$ was $4.5 \mathrm{e}-4$. The $\mathrm{R}^{2}$ value of the proposed model on the iPhone sales data was 0.99 . On comparison with the Bass diffusion model, the potential sales was just $1.83 \mathrm{e}+03$, the coefficient of innovation(p) was $3.97 \mathrm{e}-3$, the coefficient of imitation(q) was $4.85 \mathrm{e}-01$, and the saturation of market will be only about 2020. The comparison plot with the Bass [3] model is as shown in Figure 3. This shows, the Apple's business strategies on iPhone sales with different generation products and competing with other smart phone brands the market saturation will be reached at 2070 .

\section{Conclusion}

Under constant environment and continuing the present business exercises, the proposed business diffusion model performed the better fit than Bass model. This paper proposes a model on the extension of business with respect to its 


\section{Thakur Dhakal}

sales volume in certain community with a certain communication channel. While analysing the model with Apple iPhone sales data of 2007 to 2017 and compared with the Bass diffusion model it is found the better fit. The parameters were estimated using the non-linear least square method. The iPhone sales under the present business strategies the Apple can hold its market up to 2070 then it reaches the saturation point. Thus, this model can be a good forecasting tool to analyse the business diffusion process.

\section{Acknowledgements}

I would like to acknowledge professor Dae-Eun Lim (Ph.D.), Department of Industrial Engineering, Kangwon National University for fruitful suggestions and good research environment.

\section{References}

[1] E. M. Rogers, (2003). Diffusion of Innovations, New York: The Free Press.

[2] Statista,"https://www.statista.com/statistics/263401/global-apple-iphonesales-since-3rd-quarter-2007/," 2018. [Online]. Available: https://www. statista.com/statistics/263401/global-apple-iphone-sales-since-3rdquarter-2007.

[3] F. M. Bass, (1969). "A new-product growth model for consumer durables," Management Science, vol. 15, pp. 215-227.

[4] V. Mahajan, . E. Muller and Y. Wind, "New-Product Diffusion Models," Springer Science and Business Media, vol. 11, 2000.

[5] J.Arndt, (1967). "Role of Product-Related Conversations in the Diffusion of a New Product," Journal of Marketing Research, vol. 4, pp. 291-295.

[6] R. E. Frank, M. William F. and M. Donald G. (1964). "The Determinants of Innovative Behavior With Respect to a Branded, Frequently Purchased Food Product," in Proceedings of the American Marketing Association, L. G. Smith, ed. Chicago.

[7] C. W. J. King, (1963). "Fashion Adoption: A Rebuttal to the 'Trickle Down' Theory," in Proceedings of the American Marketing Association, S. A. Greyser, ed. Chicago.

[8] T. S. Robertson, (1967). "Determinants of Innovative behavior," in In Proceedings of the American Marketing Association, R. Moyer, ed. Chicago. 
[9] A. J. Silk, (1966). "Overlap Among Self-Designated Opinion Leaders: A Study of Selected Dental Products and Services," Journal of Marketing Research, vol. 3, no. 3, 255-259.

[10] J. Massiani and A. Gohs, (2015). "The choice of Bass model coefficients to forecast diffusion for innovative products: an empirical investigation for new automotive technologies," Research in Transportation Economics, vol. 50, pp. 17-28.

[11] C. Chung, S. Niu and C. Sriskandarajah, (2012). "A sales forecast model for short-life-cycle products: new releases at blockbuster," Production and Operations Management, vol. 21, no. 5, pp. 851-873.

[12] Z. Ismail and N. Abu, (2013). "A study on new product demand forecasting based on bass diffusion model," Journal of Mathematics and Statistics, vol. 9, no. 2, pp. 84-90.

[13] T. Kim and J. Hong, (2015). "Bass model with integration constant and its applications on initial demand and left-truncated data," Technological Forecasting and Social Change, vol. 95, pp. 120-134.

[14] D. B. Jun and Y. S. Park, (1999). "A Choice-Based Diffusion Model for Multiple Generation of Products," Technological Forecasting and Social Change Multiple Generations of Products, vol. 61, pp. 45-58.

[15] J. A. Norton, and F. M. Bass, (1987). "A diffusion theory model of adoption and substitution for successive generation of high-technology products," Management Science, vol. 33, no. 9, pp. 1069-1086.

[16] W. M. Speece and L. d. MacLachlan, (1992). "Forecasting Fluid Milk Package Type with a Multi-generation New Product Diffusion Model," IEEE Transactions on Engineering Management, vol. 39, no. 2 pp. 169-75.

[17] J. H. Pae and D. R. Lehmann, (2003). "Multigeneration Innovation Diffusion: The Impact of Intergeneration Time," Journal of the Academy of Marketing Science, vol. 31, no. 1, pp. 36-45.

[18] N. Kim, D. R. Chang and A. D. Shocker, (2000). "Modeling Intercategory and Generational Dynamics for A Growing Information Technology Industry," Management Science, vol. 46, no. 4, pp. 496-512.

[19] A. Kurawarwala and H. Matsuo, (1998). "Product growth models for medium-term forecasting of short life cycle products," Technological Forecasting and Social, vol. 57, no. 3, pp. 169-196.

[20] X. Shi, P. Chumnumpan and K. Fernandes, (2014). "A diffusion model for service products," Journal of Services Marketing, vol. 28, no. 4, pp. 331-341. 
[21] B. Robinson and C. Lakhani, (1975). "Dynamic Price Models for New Product Planing," Management Science, vol. 10, pp. 1113-1122.

[22] S. Kalish, (1985). "A New Product Adoption Model with Pricing, Advertising, and Uncertainity," Management Science, vol. 31, pp. 1569-1585.

[23] F. Bass, D. Jain and T. Krishnan, (2000). "Modeling the marketing-mix influence in New-product diffusion," in V. Mahajan, E. Muller an Y. Wind (eds.) New Product Diffusion Models, Boston, MA, Kluwer Academic Publishers.

[24] L. V. Bertalanffy, (1957). "Quantitative laws in metabolism and growth," Q. Rev. Biol., vol. 32, pp. 217-231.

[25] C. Easingwood, V. Mahajan and E. Muller, (1983). "A Non-Uniform Influence Innovation Diffusion Model of New Product Acceptance," Marketing Science, vol. 2, pp. 273-295.

[26] D. Horsky and L. Simon, (1983). "Advertising and the difusion of new products," Marketing Science, vol. 2, pp. 1-18.

[27] R. Bewley and D. Fiebig, (1988). "A Flexible Logistic Growth Model with Applications in Telecommunications," International Journal of Forecasting, vol. 4, pp. 177-192.

\section{Biography}

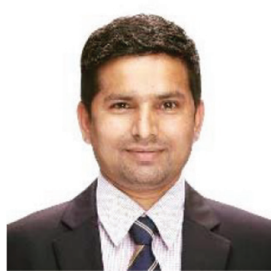

Thakur Dhakal is a Ph.D. student in department of Industrial Engineering at the Kangwon National University, South Korea since spring 2017. He did his M.Sc. degree in Automotive Engineering from Kangwon National University in 2016. He attended the Tribhuvan University, Institute of Engineering, where he achieved the Bachelor's degree in Industrial Engineering in 2010. He is a registered Industrial Engineer in Nepal. He worked as an Engineer in Constitution Assembly Hall Nepal after his BS. He is also 
a country representative on of SMI Co.Ltd. South Korea to Nepal for Business Development. His research interest is to analyze the dynamics of systems, automotive controls, strategy management, technology diffusion management, and so on. His Ph.D. work centers innovation diffusion and strategies to launch the new technology. 
